\title{
Association of Short-Term Exposure to Ambient Fine Particulate Matter with Skin Symptoms in Schoolchildren: A Panel Study in a Rural Area of Western Japan
}

\author{
Masanari Watanabe ${ }^{1, *}$, Hisashi Noma ${ }^{2}$, Jun Kurai ${ }^{1}$, Hiroyuki Sano ${ }^{3}$, Kyoko Iwata ${ }^{1,4}$, \\ Degejirihu Hantan ${ }^{1}$, Yuji Tohda ${ }^{3}$ and Eiji Shimizu ${ }^{1}$ \\ 1 Department of Respiratory Medicine and Rheumatology, Faculty of Medicine, Tottori University, \\ 36-1 Nishi-cho, Yonago 683-8504, Japan; junkurajun@gmail.com (J.K.); iwatak@mfc.or.jp (K.I.); \\ degujirefu@med.tottori-u.ac.jp (D.H.); eiji@med.tottori-u.ac.jp (E.S.) \\ 2 Department of Data Science, Institute of Statistical Mathematics, 10-3 Midori-cho, Tachikawa, \\ Tokyo 190-8562, Japan; noma@ism.ac.jp \\ 3 Department of Respiratory Medicine and Allergology, Faculty of Medicine, \\ Kinki University, 377-2 Ohnohigashi, Osakasayama 589-0014, Japan; \\ hsano@med.kindai.ac.jp (H.S.); tohda@med.kindai.ac.jp (Y.T.) \\ 4 Mio Fertility Clinic, Reproductive Centre, 2-1-1 Kuzumo-minami, Yonago 683-0008, Japan \\ * Correspondence: watanabm@grape.med.tottori-u.ac.jp; Tel.: +81-859-38-6537
}

Academic Editor: Michael S. Breen

Received: 12 January 2017; Accepted: 11 March 2017; Published: 13 March 2017

\begin{abstract}
Numerous studies have unmasked the deleterious effects of particulate matter less than $2.5 \mu \mathrm{m}\left(\mathrm{PM}_{2.5}\right)$ on health. However, epidemiologic evidence focusing on the effects of $\mathrm{PM}_{2.5}$ on skin health remains limited. An important aspect of Asian dust (AD) in relationship to health is the amount of $\mathrm{PM}_{2.5}$ contained therein. Several studies have demonstrated that $\mathrm{AD}$ can aggravate skin symptoms. The current study aimed to investigate the effects of short-term exposure to $\mathrm{PM}_{2.5}$ and $\mathrm{AD}$ particles on skin symptoms in schoolchildren. A total of 339 children recorded daily skin symptom scores during February 2015. Light detection and ranging were used to calculate AD particle size. Generalized estimating equation logistic regression analyses were used to estimate the associations among skin symptoms and the daily levels of $\mathrm{PM}_{2.5}$ and $\mathrm{AD}$ particles. Increases in the levels of $\mathrm{PM}_{2.5}$ and $\mathrm{AD}$ particles were not related to an increased risk of skin symptom events, with increases of $10.1 \mu \mathrm{g} / \mathrm{m}^{3}$ in $\mathrm{PM}_{2.5}$ and $0.01 \mathrm{~km}^{-1}$ in AD particles changing odds ratios by 1.03 and 0.99 , respectively. These results suggest that short-term exposure to $\mathrm{PM}_{2.5}$ and $\mathrm{AD}$ does not impact skin symptoms in schoolchildren.
\end{abstract}

Keywords: ambient particulate matter; Asian dust; particulate matter less than $2.5 \mu \mathrm{m}$; schoolchildren; skin symptoms

\section{Introduction}

Ambient particulate matter (PM) is a mixture of solid particles and liquid droplets originating from various natural and anthropogenic sources and comprises an important source of air pollutants [1]. Clinical, mechanistic, and epidemiological evidence have demonstrated adverse health effects from short-term and long-term exposure to ambient PM; these adverse influences are of concern to governments of various countries as well as the World Health Organization [2-4]. However, most epidemiological studies regarding the negative health effects of ambient PM have focused on respiratory and cardiovascular injuries. 
The skin is the outermost barrier and is directly exposed to various environmental pollutants. Ultraviolet radiation from sunlight has been the most studied environmental hazard, and its consequences on skin are well established [5]. While a number of clinical and epidemiological studies highlight the associations with ambient PM and health effects, very little research is available to date concerning skin effects $[5,6]$. Furthermore, the exact mechanism of skin damage by ambient PM has yet to be elucidated. However, diesel-exhaust particles, which are an important source of PM less than $2.5 \mu \mathrm{m}$ in diameter $\left(\mathrm{PM}_{2.5}\right)$, have been shown to induce a strong inflammatory response in human skin cells $[7,8]$. Asian dust (AD), which originates in the deserts of East Asia, is the second strongest source of dust emissions worldwide (accounting for about $20 \%$ of the global total) and increases the concentrations of air pollutants including $\mathrm{PM}_{2.5}[9,10]$. In addition, recent studies reported that $\mathrm{AD}$ was associated with an increase in mortality as well as emergency treatment for cardiovascular and respiratory diseases [11-14]. Moreover, Otani et al. found an adverse effect of AD on skin health in Japan [15]. These results suggest that short-term exposure to $\mathrm{PM}_{2.5}$ can aggravate skin symptoms.

Few studies have investigated the association between ambient PM and skin symptoms in children. Therefore, this study aimed to investigate the association between skin symptoms in children and short-term exposure to $\mathrm{PM}_{2.5}$ in western Japan. We also studied the relationship between skin symptoms in children and $\mathrm{AD}$ because $\mathrm{AD}$ is one of the important sources of $\mathrm{PM}_{2.5}$ in Japan.

\section{Materials and Methods}

\subsection{Study Design}

In this panel study, skin symptoms of schoolchildren were monitored daily in the morning during February 2015. The study was performed in Matsue, the capital city of Shimane Prefecture, in southwest Japan. This city houses approximately 200,000 individuals and covers an area of $530.2 \mathrm{~km}^{2}$. Four elementary schools were selected from a total of 35 in Matsue City because these four schools are located near principal roads in the central part of Matsue City and are within $10 \mathrm{~km}$ of each other as well as from the observatory for monitoring air pollution in Matsue City. All elementary schools agreed to participate in the study. All subjects lived within a 1-km radius of the schools. A total of 345 students aged 10 to 12 years in 2015 were enrolled.

The study was approved by the institutional ethics committee (Ethics Committee of the Faculty of Medicine, Tottori University, approval number 2473). The study was also approved by the Matsue City Board of Education. The children and their parents were informed by teachers and provided written consent.

\subsection{Recording of Daily Skin Symptoms}

In January 2015, the schoolteachers provided information regarding the sex, height, and weight of each child based on physical measurements obtained by each school and recorded this information in a logbook for recording skin symptoms by teachers. The parents filled their children's data concerning presence of asthma, allergic rhinitis, allergic conjunctivitis, atopic dermatitis, and food allergies in the logbook. The subjects were considered to have asthma if they met any of the following criteria in the past 12 months: diagnosis of asthma by a pediatrician, presence of wheezing, use of asthma medication, or a visit to a hospital for asthma. The subjects were considered to have allergic rhinitis, allergic conjunctivitis, atopic dermatitis, and/or food allergy if they met any of the following criteria in the past 12 months: diagnosis of any of these conditions by a pediatrician, use of medication for any of these conditions, or a visit to a hospital for any of these conditions. From 1 February 2015 to 28 February 2015, each child recorded daily scores for itchiness and rash as skin symptoms; scores were recorded as 0 (no symptoms), 1 (mild symptoms), or 2 (severe symptoms). Scores were recorded between 8:00 a.m. and 9:00 a.m. All children went to school on foot and were potentially exposed to any air pollutants. 


\subsection{Measurement of Air Pollutant Levels}

Daily average concentrations of $\mathrm{PM}_{2.5}$, sulfur dioxide $\left(\mathrm{SO}_{2}\right)$, nitrogen dioxide $\left(\mathrm{NO}_{2}\right)$, and ozone in Matsue City were calculated based on data from the Japanese Ministry of the Environment, which monitors and reports hourly concentrations of these air pollutants. Meteorological variables, such as daily average levels of temperature, humidity, wind speed, and atmospheric pressure, were obtained from the Japan Meteorological Agency. The data were used to examine the associations between changes in skin symptoms and air pollutant levels.

Light Detection and Ranging (LIDAR) depolarization measurements performed simultaneously at two wavelengths can be used to identify non-spherical dust particles such as airborne sand dust particles and spherical particles such as air pollution aerosols in real time $[16,17]$. The LIDAR system can be used to measure the level of AD [16,17]; recently, a few studies from Japan used LIDAR data to estimate the effects of AD on health [18-20]. Daily particle levels were determined based on the median value of 96 measurements collected over a 24-h period from midnight of one day to midnight of the next day. The daily levels were only calculated when the number of available measurements exceeded $50 \%$ of the total number of measurements. This study used values measured from $120 \mathrm{~m}$ to $150 \mathrm{~m}$ above ground, which is the minimum altitude required by LIDAR systems to measure non-spherical and spherical particles. Data for AD concentrations from LIDAR were obtained from the Matsue observatory.

\subsection{Statistical Analysis}

To adequately address correlations among repeated measurements within a subject, generalized estimating equation (GEE) logistic regression analyses were used to estimate the associations among the daily skin symptoms of children and the daily average levels of $\mathrm{PM}_{2.5}, \mathrm{SO}_{2}, \mathrm{NO}_{2}$, and ozone and median levels of AD particles [21,22]. A skin symptom event was defined as a daily skin symptom score $\geq 2$. The GEE logistic regression models included individual characteristics (sex, height, weight, asthma, allergic rhinitis, allergic conjunctivitis, atopic dermatitis, and food allergies) and meteorological variables (daily temperature, humidity, and atmospheric pressure) [23-26]. Estimates are given as the odds ratio in skin symptom events per interquartile range (IQR) change of $\mathrm{PM}_{2.5}, \mathrm{SO}_{2}, \mathrm{NO}_{2}$, ozone, and AD concentrations, with 95\% confidence intervals (CIs). The working correlation matrices were set to exchangeable, and robust variance estimators were adopted for constructing the CIs for the odds ratios. Multiple imputations with chained equations were used for treating missing data; this adequately addresses the uncertainty of multiply generated prediction values for missing data [27]. The two-pollutant models were applied to different combinations of air pollutants $\left(\mathrm{SO}_{2}\right.$, $\mathrm{NO}_{2}$, and ozone) to assess the stability of the effect of $\mathrm{PM}_{2.5}$ and $\mathrm{AD}$ on skin symptoms after adjustment for individual characteristics (age, sex, height, weight, and presence of asthma, allergic rhinitis, allergic conjunctivitis, atopic dermatitis, and food allergies), and meteorological variables (temperature, humidity, and atmospheric pressure). The GEE analyses were performed using R version 3.2.2 (R Foundation for Statistical Computing, Vienna, Austria).

\section{Results}

\subsection{Subject Characteristics}

Of the 345 children who were recruited, six were excluded because they failed to maintain a daily record of skin symptoms. The characteristics of the remaining 339 children are shown in Table 1 . Data were missing for sex $(n=2)$, age $(n=3)$, height $(n=6)$, and body weight $(n=8)$. 
Table 1. Characteristics of the 339 children included in this study.

\begin{tabular}{lcc}
\hline Characterristics & \multicolumn{2}{c}{ Value } \\
\hline Boy/Girl (number) & \multicolumn{2}{c}{$170 / 167$} \\
\hline Age (number) & \multicolumn{2}{c}{} \\
10-year old & 42 & $(12.4)$ \\
11-year old & 293 & $(86.4)$ \\
12-year old & 1 & $(0.3)$ \\
\hline Height $(\mathrm{cm})$ & 144.6 & \pm 7.1 \\
\hline Weight $(\mathrm{kg})$ & 36.4 & \pm 7.1 \\
\hline Allergic disease (number) & & \\
$\quad$ Asthma & 36 & $(10.6)$ \\
Allergic rhinitis & 54 & $(15.9)$ \\
Allergic conjunctivitis & 8 & $(2.4)$ \\
Atopic dermatitis & 26 & $(7.7)$ \\
Food allergies & 16 & $(4.7)$ \\
\hline Data are shown as mean \pm standard deviation or $n(\%)$.
\end{tabular}

3.2. Daily Levels of Temperature, Humidity, Atmospheric Pressure, $\mathrm{PM}_{2.5}, \mathrm{NO}_{2}, \mathrm{Ozone}, \mathrm{SO}_{2}$, and AD Particles

Table 2 shows the daily levels of temperature, humidity, atmospheric pressure, wind speed, $\mathrm{PM}_{2.5}$, $\mathrm{NO}_{2}$, ozone, $\mathrm{SO}_{2}$, and AD particles from 1 February 2015 to 28 February 2015.

Table 2. Average meteorological and air contaminant levels from 1 to 28 February 2015.

\begin{tabular}{cc}
\hline Valuables & Value \\
\hline Temperature (Celsius) & $5.4 \pm 2.3$ \\
Humidity $(\%)$ & $72.1 \pm 8.0$ \\
Atmospheric pressure $(\mathrm{hPa})$ & $1016.6 \pm 5.5$ \\
Wind $(\mathrm{m} / \mathrm{s})$ & $4.0 \pm 2.0$ \\
$\mathrm{PM}_{2.5}\left(\mu \mathrm{g} / \mathrm{m}^{3}\right)$ & $13.0 \pm 7.5$ \\
$\mathrm{NO}_{2}(\mathrm{ppb})$ & $2.5 \pm 1.5$ \\
$\mathrm{Ozone}(\mathrm{ppb})$ & $38.1 \pm 7.0$ \\
$\mathrm{SO}_{2}(\mathrm{ppb})$ & $3.0 \pm 1.9$ \\
Asian dust particles $\left(\mathrm{km}^{-1}\right)$ & $0.02 \pm 0.03$ \\
\hline Data are shown as mean \pm standard deviation.
\end{tabular}

\subsection{Skin Symptoms}

Table 3 shows the odds ratios for an IQR increase in skin symptoms based on levels of $\mathrm{PM}_{2.5}$, $\mathrm{NO}_{2}$, ozone, $\mathrm{SO}_{2}$, and $\mathrm{AD}$ particles. Increases in the levels of $\mathrm{PM}_{2.5}, \mathrm{NO}_{2}$, ozone, $\mathrm{SO}_{2}$, and $\mathrm{AD}$ particles were not related to an increased risk of skin symptom events in children either with or without atopic dermatitis. The cumulative total summary of the symptom score was $5395(56.8 \%)$ for a score of 1,800 $(8.4 \%)$ for $2,84(0.9 \%)$ for 3 , and $3213(33.8 \%)$ for non-observed. In a two-pollutant model adjusted for $\mathrm{NO}_{2}$, ozone, and $\mathrm{SO}_{2}, \mathrm{PM}_{2.5}$ and $\mathrm{AD}$ particles were not associated with risk of skin symptom events (Tables 4 and 5). 
Table 3. Multivariate analysis using generalized estimating equation (GEE) logistic regression models to assess the association between skin symptoms and interquartile range (IQR) changes in the air contaminant concentrations.

\begin{tabular}{ccccc}
\hline \multirow{2}{*}{ Exposure Metric } & \multicolumn{4}{c}{ Children $(\boldsymbol{n}=\mathbf{3 3 9 )}$} \\
\cline { 2 - 5 } & IQR & Odds Ratio & $\mathbf{9 5 \%}$ CI & $\boldsymbol{p}$ Value \\
\hline $\mathrm{PM}_{2.5}$ & $10.1 \mu \mathrm{\mu g} / \mathrm{m}^{3}$ & 1.03 & 0.80 to 1.33 & $\mathrm{NS}$ \\
$\mathrm{NO}_{2}$ & $1.9 \mathrm{ppb}$ & 0.99 & 0.80 to 1.23 & $\mathrm{NS}$ \\
$\mathrm{Ozone}_{\mathrm{SO}}$ & $11.3 \mathrm{ppb}$ & 0.79 & 0.56 to 1.12 & $\mathrm{NS}$ \\
$\mathrm{AD}$ particles & $2.5 \mathrm{ppb}$ & 1.07 & 0.85 to 1.35 & $\mathrm{NS}$ \\
& $0.01 \mathrm{~km}^{-1}$ & 0.99 & 0.92 to 1.06 & $\mathrm{NS}$ \\
\hline
\end{tabular}

CI, confidence interval; NS, not significant.

Table 4. Estimated effects of $\mathrm{PM}_{2.5}$ on skin symptoms in the two-pollutant model after adjustment for $\mathrm{NO}_{2}$, ozone, and $\mathrm{SO}_{2}$.

\begin{tabular}{cccc}
\hline Adjustment & Odds Ratio & $\mathbf{9 5 \%}$ CI & $p$ Value \\
\hline Adjusted for $\mathrm{NO}_{2}$ & 1.20 & 0.65 to 2.24 & NS \\
Adjusted for ozone & 0.98 & 0.72 to 1.34 & NS \\
Adjusted for $\mathrm{SO}_{2}$ & 1.05 & 0.83 to 1.33 & NS \\
\hline
\end{tabular}

CI, confidence interval; NS, not significant.

Table 5. Estimated effects of $\mathrm{AD}$ particles on skin symptoms in the two-pollutant model after adjustment for $\mathrm{NO}_{2}$, ozone, and $\mathrm{SO}_{2}$.

\begin{tabular}{cccc}
\hline Adjustment & Odds Ratio & $\mathbf{9 5 \%}$ CI & $p$ Value \\
\hline Adjusted for $\mathrm{NO}_{2}$ & 0.98 & 0.89 to 1.08 & NS \\
Adjusted for ozone & 0.95 & 0.88 to 1.03 & NS \\
Adjusted for $\mathrm{SO}_{2}$ & 0.99 & 0.92 to 1.06 & NS \\
\hline
\end{tabular}

CI, confidence interval; NS, not significant.

\section{Discussion}

A number of studies have unmasked the deleterious effects of ambient PM on internal organs [2-4]. It has gradually become clear that there are four potential mechanisms by which ambient PM exerts adverse effects on the skin, including generation of free radicals, induction of cutaneous inflammatory cascades, activation of an aryl hydrocarbon receptor (AhR)-dependent mechanism, and alteration of cutaneous microflora $[5,28]$. However, to the best of our knowledge, the epidemiologic evidence focusing on the effects of ambient PM on skin health remains limited. Especially, in the relationship between short-term exposure to ambient PM and skin health, current evidence is lacking. Therefore, the present study investigated associations among daily $\mathrm{PM}_{2.5}$ and skin symptoms in schoolchildren, but found no significant relationship. Similarly, $\mathrm{NO}_{2}$, ozone, $\mathrm{SO}_{2}$, and $\mathrm{AD}$ particles were also not associated with skin symptoms. These results suggest that short-term exposure to air pollutants does not have an impact on skin symptoms of schoolchildren in Japan.

Kim et al. recently completed a small longitudinal study elucidating a significant association between outdoor levels of $\mathrm{PM}_{2.5}$ and skin symptoms in children with atopic dermatitis [29]. They also concluded that $\mathrm{NO}_{2}$ and volatile organic compounds may aggravate atopic dermatitis; thus, patients with skin disease may be more sensitive to exposure to $\mathrm{PM}_{2.5}$ than are subjects without skin disease. In the current study, our statistical analysis was adjusted for the presence of atopic dermatitis as an individual characteristic. Notwithstanding, irrespective of the presence of atopic dermatitis, the present study found no association with $\mathrm{PM}_{2.5}$ and skin symptoms in schoolchildren. 
Kim et al. estimated the seasonal associations among skin symptoms and $\mathrm{PM}_{2.5}$ for winter, spring, summer, and autumn. They found a significant association with skin symptoms and $\mathrm{PM}_{2.5}$ only in winter, which exhibited the highest $\mathrm{PM}_{2.5}$ level among the four seasons. The levels of $\mathrm{PM}_{2.5}$ in Seoul, South Korea, where research by Kim et al. was conducted, exceeded $20 \mu \mathrm{g} / \mathrm{m}^{3}$ and were higher than those reported in the present study. Accordingly, the difference in results between the study of Kim et al. and the present study may depend on differences in levels of $\mathrm{PM}_{2.5}$. Alternatively, low-concentration or short-term exposure to $\mathrm{PM}_{2.5}$ may be insufficient to aggravate skin symptoms.

There are many reports suggesting that $\mathrm{PM}_{2.5}$ contributes to various skin diseases, such as inflammatory skin disease, androgenetic alopecia, and skin cancer [30-32]. Furthermore, Vierkötter et al. found a strong association of premature skin aging with exposure to $\mathrm{PM}_{2.5}$ in the elderly [33]. Similarly, other air pollutants, such as $\mathrm{NO}_{2}$, ozone, and volatile organic compounds, also have adverse effects on skin health $[31,34]$. Recent studies suggest the possible mechanisms by which air pollutants such as $\mathrm{PM}_{2.5}$ cause adverse skin effects; such mechanisms include increasing inflammatory cytokines, reducing the barrier function of skin, and activating reactive oxygen species and AhR [2-4,6,33]. Thus, $\mathrm{PM}_{2.5}$ may adversely affect skin health in schoolchildren. To better estimate the effects of $\mathrm{PM}_{2.5}$ on skin health and skin symptoms in children, objective evaluation methods such as score of intrinsic and extrinsic skin aging may be needed.

An important aspect of dust storms in relationship to health issues is the amount of $\mathrm{PM}_{2.5}$ that they contain. $\mathrm{AD}$ is also a serious health concern because of the associated heavy pollution, and it has been associated with increased mortality, emergency treatment for cardiovascular diseases, and hospitalization for pneumonia [14,35-37]. Recently, several studies from Japan demonstrated an association between $\mathrm{AD}$ and skin symptoms in healthy adult subjects $[10,11,38,39]$. Therefore, the present study also estimated the daily levels of $\mathrm{AD}$ particles and skin symptoms in schoolchildren using LIDAR data but found no such relationship. However, the studies reporting a significant association with $\mathrm{AD}$ and skin symptoms estimated the effect of heavy $\mathrm{AD}$ on skin health. In these studies, heavy $\mathrm{AD}$ was defined as a density greater than $0.6 \mathrm{~km}^{-1}$ or $1.0 \mathrm{~km}^{-1}$. In the present study, the average level of $\mathrm{AD}$ particles was $0.02 \mathrm{~km}^{-1}$. Thus, low-concentration exposure to AD particles may be insufficient to aggravate skin symptoms. Alternatively, the effects of AD on skin health may differ between adults and children.

There are several limitations in the current study. First, the study duration, which was one month, may not have been long enough to estimate the effects of short-term exposure to ambient PM on skin health. However, our previous one-month study found a significant negative association with ambient PM and respiratory function in schoolchildren [23], suggesting that one month may be sufficient time. Second, this also restricted any assessment of seasonal variation. Regardless, according to the results of Kim et al. [29], $\mathrm{PM}_{2.5}$ during winter was the most concerning with respect to the deleterious effects of ambient PM on skin health. Thus, although the present study was conducted during the most suitable season, such effects may depend on the composition of $\mathrm{PM}_{2.5}$. Third, skin symptom scores were not validated because validated skin symptom scores were not available in Japan at the time of the study. Therefore, as in previous studies which estimated the association with $\mathrm{PM}_{2.5}$ and respiratory symptoms, skin symptom scores were reported as 0 (no symptoms), 1 (mild symptoms), or 2 (severe symptoms) [40]. Finally, we were unable to measure the individual amount of exposure to particulate air pollutants.

\section{Conclusions}

Short-term exposure to $\mathrm{PM}_{2.5}$ was not associated with skin symptoms in schoolchildren. $\mathrm{AD}$ particles are an important source of $\mathrm{PM}_{2.5}$ in Japan. However, there was no relationship between AD particles and skin symptoms. Neither $\mathrm{PM}_{2.5}$ nor AD particles aggravated the skin symptoms of schoolchildren. 
Acknowledgments: We would like to thank Atsushi Shimizu (National Institute for Environmental Studies) for providing LIDAR data. This research was supported by the Environmental Research and Technology Development Fund (5-1453) of the Japanese Ministry of the Environment and Tottori prefecture. We would like to thank Editage (www.editage.jp) for English-language editing.

Author Contributions: Masanari Watanabe, Jun Kurai, Hiroyuki Sano, and Yuji Tohda conceived the study. Masanari Watanabe, Hisashi Noma, Jun Kurai, Hiroyuki Sano, Yuji Tohda, and Eiji Shimizu designed the study. Masanari Watanabe, Hisashi Noma, and Jun Kurai wrote the manuscript. Masanari Watanabe, Jun Kurai, Kyoko Iwata, and Degejirihu Hantan contributed to data collection. Masanari Watanabe, Jun Kurai, Kyoko Iwata, and Degejirihu Hantan performed the laboratory work. Masanari Watanabe, Hisashi Noma, and Kyoko Iwata performed the statistical analysis and interpretation of the results. Masanari Watanabe, Hisashi Noma, and Jun Kurai contributed to critical revision of important intellectual content. All authors read and approved the final manuscript.

Conflicts of Interest: The authors declare no conflict of interest.

\section{References}

1. Wilson, W.E.; Chow, J.C.; Claiborn, C.; Fusheng, W.; Engelbrecht, J.; Watson, J.G. Monitoring of particulate matter outdoors. Chemosphere 2002, 49, 1009-1043. [CrossRef]

2. World Health Organization. Air Quality Guidelines. Global Update 2005; World Health Organisation Regional Office for Europe: Copenhagen, Denmark, 2006; pp. 217-306.

3. World Health Organization. Health Relevance of Particulate Matter from Various Sources; Report on a WHO Workshop: Bonn, Germany, 26-27 March 2007. Available online: http:/ /www.euro.who.int/data/assets/ pdf_file/0007/78658/E90672.pdf (accessed on 4 January 2017).

4. Health Effects Institute. Health Effects of Outdoor Air Pollution in Developing Countries of Asia: A Literature Review; Special Report 15; Health Effects Institute: Boston, MA, USA, 2004.

5. Mancebo, S.E.; Wang, S.Q. Recognizing the impact of ambient air pollution on skin health. J. Eur. Acad. Dermatol. Venereol. 2015, 29, 2326-2332. [CrossRef] [PubMed]

6. Krutmann, J.; Liu, W.; Li, L.; Pan, X.; Crawford, M.; Sore, G.; Seite, S. Pollution and skin: From epidemiological and mechanistic studies to clinical implications. J. Dermatol. Sci. 2014, 76, 163-168. [CrossRef] [PubMed]

7. Ushio, H.; Nohara, K.; Fujimaki, H. Effect of environmental pollutants on the production of pro-inflammatory cytokines by normal human dermal keratinocytes. Toxicol. Lett. 1999, 105, 17-24. [CrossRef]

8. Ma, C.; Wang, J.; Luo, J. Activation of nuclear factor kappa B by diesel exhaust particles in mouse epidermal cells through phosphatidylinositol 3-kinase/Akt signaling pathway. Biochem. Pharmacol. 2004, 67, 1975-1983. [CrossRef] [PubMed]

9. Tanaka, T.Y.; Chiba, M. A numerical study of the contribution of dust source regions to the global dust budget. Glob. Planet Chang. 2006, 52, 88-104. [CrossRef]

10. Onishi, K.; Kurosaki, Y.; Otani, S.; Yoshida, A.; Sugimoto, N.; Kurozawa, Y. Atmospheric transport route determines components of Asian dust and health effects in Japan. Atmos. Environ. 2012, 49, 94-102. [CrossRef]

11. Mu, H.; Battsetseg, B.; Ito, T.Y.; Otani, S.; Onishi, K.; Kurozawa, Y. Health effects of dust storms: Subjective eye and respiratory system symptoms in inhabitants in Mongolia. J. Environ. Health 2011, 73, 18-20. [PubMed]

12. Zhang, X.; Zhao, L.; Tong, D.Q.; Wu, G.; Dan, M.; Teng, B. A systematic review of global desert dust and associated human health effects. Atmosphere 2016, 7, 158. [CrossRef]

13. Lee, J.W.; Lee, K.K. Effects of Asian dust events on daily asthma patients in Seoul, Korea. Meteorol. Appl. 2014, 21, 202-209. [CrossRef]

14. Chan, C.C.; Chuang, K.J.; Chen, W.J.; Chang, W.T.; Lee, C.T.; Peng, C.M. Increasing cardiopulmonary emergency visits by long-range transported Asian dust storms in Taiwan. Environ. Res. 2008, 106, 393-400. [CrossRef] [PubMed]

15. Otani, S.; Onishi, K.; Mu, H.; Yokoyama, Y.; Hosoda, T.; Okamoto, M.; Kurozawa, Y. The relationship between skin symptoms and allergic reactions to Asian dust. Int. J. Environ. Res. Public Health 2012, 9, 4606-4614. [CrossRef] [PubMed]

16. Sugimoto, N.; Lee, C.H. Characteristics of dust aerosols inferred from LIDAR depolarization measurements at two wavelengths. Appl. Opt. 2006, 45, 7468-7474. [CrossRef] [PubMed]

17. Sugimoto, N.; Matsui, I.; Shimizu, A.; Nishizawa, T.; Hara, Y.; Xie, C.; Uno, I.; Yumimoto, K.; Wang, Z.; Yoon, S.C. Lidar network observations of tropospheric aerosols. Proc. SPIE 2008, 7153, 71530A. 
18. Ueda, K.; Shimizu, A.; Nitta, H.; Inoue, K. Long-range transported Asian Dust and emergency ambulance dispatches. Inhal. Toxicol. 2012, 24, 858-867. [CrossRef] [PubMed]

19. Kanatani, K.T.; Hamazaki, K.; Inadera, H.; Sugimoto, N.; Shimizu, A.; Noma, H.; Onishi, K.; Takahashi, Y.; Itazawa, T.; Egawa, M.; et al. Effect of desert dust exposure on allergic symptoms: A natural experiment in Japan. Allergy Asthma Immunol. 2016, 116, 425-430. [CrossRef] [PubMed]

20. Nakamura, T.; Hashizume, M.; Ueda, K.; Shimizu, A.; Takeuchi, A.; Kubo, T.; Hashimoto, K.; Moriuchi, H.; Odajima, H.; Kitajima, T.; et al. Asian Dust and Pediatric Emergency Department Visits Due to Bronchial Asthma and Respiratory Diseases in Nagasaki, Japan. J. Epidemiol. 2016, 26, 593-601. [CrossRef] [PubMed]

21. Laird, N.M.; Ware, J.H. Random-effects models for longitudinal data. Biometrics 1982, 38, 963-974. [CrossRef] [PubMed]

22. Verbeke, G.; Molenberghs, G. Linear Mixed Models for Longitudinal Data, 2nd ed.; Springer: New York, NY, USA, 2009.

23. Higashi, T.; Kambayashi, Y.; Ohkura, N.; Fujimura, M.; Nakai, S.; Honda, Y.; Saijoh, K.; Hayakawa, K.; Kobayashi, F.; Michigami, Y.; et al. Effects of Asian dust on daily cough occurrence in patients with chronic cough: A panel study. Atmos. Environ. 2014, 92, 506-513. [CrossRef]

24. Cesaroni, G.; Badaloni, C.; Porta, D.; Forastiere, F.; Perucci, C.A. Comparison between various indices of exposure to traffic-related air pollution and their impact on respiratory health in adults. Occup. Environ. Med. 2008, 65, 683-690. [CrossRef] [PubMed]

25. Gehring, U.; Wijga, A.H.; Brauer, M.; Fischer, P.; de Jongste, J.C.; Kerkhof, M.; Oldenwening, M.; Smit, H.A.; Brunekreef, B. Traffic-related air pollution and the development of asthma and allergies during the first 8 years of life. Am. J. Respir. Crit. Care Med. 2010, 181, 596-603. [CrossRef] [PubMed]

26. Ma, L.; Shima, M.; Yoda, Y.; Yamamoto, H.; Nakai, S.; Tamura, K.; Nitta, H.; Watanabe, H.; Nishimuta, T. Effects of airborne particulate matter on respiratory morbidity in asthmatic children. J. Epidemiol. 2008, 18, 97-110. [CrossRef] [PubMed]

27. Rubin, D.B. Multiple Imputation for Nonresponse in Surveys; John Wiley: New York, NY, USA, 1987.

28. Hidaka, T.; Ogawa, E.; Kobayashi, E.H.; Suzuki, T.; Funayama, R.; Nagashima, T.; Fujimura, T.; Aiba, S.; Nakayama, K.; Okuyama, R.; et al. The aryl hydrocarbon receptor AhR links atopic dermatitis and air pollution via induction of the neurotrophic factor artemin. Nat. Immunol. 2017, 18, 64-73. [CrossRef] [PubMed]

29. Kim, J.; Kim, E.H.; Oh, I.; Jung, K.; Han, Y.; Cheong, H.K. Symptoms of atopic dermatitis are influenced by outdoor pollution. J. Allergy Clin. Immunol. 2013, 132, 495-498. [CrossRef] [PubMed]

30. Kim, K.E.; Cho, D.; Park, H.J. Air pollution and skin diseases: Adverse effects of airborne particulate matter on various skin diseases. Life Sci. 2016, 152, 126-134. [CrossRef] [PubMed]

31. Peng, F.; Xue, C.H.; Hwang, S.K.; Li, W.H.; Chen, Z.; Zhang, J.Z. Exposure to fine particulate matter associated with senile lentigo in Chinese women: A cross-sectional study. J. Eur. Acad. Dermatol. Venereol. 2017, 31, 355-360. [CrossRef] [PubMed]

32. Bernatsky, S.; Fournier, M.; Pineau, C.A.; Clarke, A.E.; Vinet, E.; Smargiassi, A. Associations between ambient fine particulate levels and disease activity in patients with systemic lupus erythematosus (SLE). Environ. Health Perspect. 2011, 119, 45-49. [CrossRef] [PubMed]

33. Vierkötter, A.; Schikowski, T.; Ranft, U.; Sugiri, D.; Matsui, M.; Krämer, U.; Krutmann, J. Airborne particle exposure and extrinsic skin aging. J. Investig. Dermatol. 2010, 130, 2719-2726. [CrossRef] [PubMed]

34. Roberts, W.E. Pollution as a risk factor for the development of melasma and other skin disorders of facial hyperpigmentation-Is there a case to be made? J. Drugs Dermatol. 2015, 14, 337-341. [PubMed]

35. Watanabe, M.; Noma, H.; Kurai, J.; Kato, K.; Sano, H.; Tatsukawa, T.; Nakazaki, H.; Yamasaki, A.; Shimizu, E. Association between pulmonary function and daily levels of sand dust particles assessed by light detection and ranging in schoolchildren in western Japan: A panel study. Allergol. Int. 2016, 65, 56-61. [CrossRef] [PubMed]

36. Bell, M.L.; Levy, J.K.; Lin, Z. The effect of sandstorms and air pollution on cause-specific hospital admissions in Taipei, Taiwan. Occup. Environ. Med. 2008, 65, 104-111. [CrossRef] [PubMed]

37. Chen, Y.S.; Sheen, P.C.; Chen, E.R.; Liu, Y.K.; Wu, T.N.; Yang, C.Y. Effects of Asian dust storm events on daily mortality in Taipei, Taiwan. Environ. Res. 2004, 95, 151-155. [CrossRef] [PubMed]

38. Otani, S.; Onishi, K.; Mu, H.; Kurozawa, Y. The effect of Asian dust events on the daily symptoms in Yonago, Japan: A pilot study on healthy subjects. Arch. Environ. Occup. Health 2011, 66, 43-46. [CrossRef] [PubMed] 
39. Onishi, K.; Otani, S.; Yoshida, A.; Mu, H.; Kurozawa, Y. Adverse health effects of Asian dust particles and heavy metals in Japan. Asia Pac. J. Public Health 2015, 27, 1719-1726. [CrossRef] [PubMed]

40. Watanabe, M.; Noma, H.; Kurai, J.; Sano, H.; Hantan, D.; Ueki, M.; Kitano, H.; Shimizu, E. A panel study of airborne particulate matter composition versus concentration: Potential for inflammatory response and impaired pulmonary function in children. Allergol. Int. 2017, 66, 52-58. [CrossRef] [PubMed]

(c) 2017 by the authors. Licensee MDPI, Basel, Switzerland. This article is an open access article distributed under the terms and conditions of the Creative Commons Attribution (CC BY) license (http:/ / creativecommons.org/licenses/by/4.0/). 